\title{
Questões sobre a emergência da heurística nas aulas de Matemática
}

\section{Questions about the emergence of heuristics in mathematics classes}

DOI: $10.46814 /$ lajdv3n1-025

Recebimento dos originais: 30/10/2020

Aceitação para publicação: 23/12/2020

\author{
Valteni Douglas Chaves \\ Mestre em Educação Matemática pela Universidade Estadual de Santa Cruz - UESC \\ Instituto Federal de Educação, Ciência e Tecnologia Baiano - IFBAIANO \\ Campus Santa Inês \\ BR 420 (Rodovia Santa Inês - Ubaíra), Zona Rural, Bahia - CEP: 45320-000 \\ E-mail: valteni.chaves@ifbaiano.edu.br \\ Marcos Rogério Neves \\ Doutor em Educação pela Universidade Federal de São Carlos - UFSCAR \\ Universidade Estadual de Santa Cruz \\ Rodovia Jorge Amado, Km 16 - Salobrinho, Ilhéus - BA, 45662-900 \\ E-mail: marcos_neves2001@yahoo.com.br
}

\begin{abstract}
RESUMO
O presente trabalho é uma pesquisa de natureza bibliográfica na qual sistematizamos e discutimos a noção de heurística, formulada de diferentes maneiras no contexto de debates científicofilosóficos sobre a Epistemologia das Ciências. A transposição para o campo da Educação Matemática é feita através da reflexão sobre situações e desafios da nossa prática docente num processo de diálogo com as contribuições de alguns autores selecionados. Tomamos como objeto matemático desta os conteúdos relacionados ao conceito de derivada e suas aplicações a partir da análise de dois livros didáticos. Como resultados da pesquisa, organizamos as questões relacionadas à heurística em três níveis, que se diferenciam pela maior ou menor consideração de elementos estruturais da Ciência Matemática. Transpondo essa análise para o campo da Educação Matemática, observamos que a noção de heurística, que já contribuiu historicamente para investigações sobre a resolução de problemas, pode ainda ser explorada como subsidio para pesquisa e ensino.
\end{abstract}

Palavras-chave: derivada e aplicações, epistemologia das ciências, heurística, resolução de problemas, ensino, matemática, ciências.

\begin{abstract}
The present work is a bibliographical research in which we systematize and discuss the notion of heuristics, formulated in different ways in the context of scientific-philosophical debates on the Epistemology of Sciences. The transposition to the field of Mathematical Education is made through the reflection on situations and challenges of our teaching practice in a process of dialogue with the contributions of some selected authors. We take as our mathematical object the contents related to the concept of derivative and its applications from the analysis of two textbooks. As a result of the research, we organized the issues related to heuristics in three levels, which are differentiated by the greater or lesser consideration of structural elements of mathematical science. Transposing this analysis to the field of Mathematical Education, we observed that the notion of heuristics, which has historically
\end{abstract}


contributed to investigations on problem solving, can still be explored as a subsidy for research and teaching.

Keywords: derived and applications, epistemology of sciences, heuristics, problem solving, teaching, mathematics, sciences.

\section{INTRODUÇÃO}

O presente trabalho é fruto de uma pesquisa em nível de mestrado ${ }^{1}$ (DOUGLAS CHAVES, 2014) na qual problematizamos e investigamos questões ligadas à nossa formação e prática profissional como docente de Matemática nos níveis educacionais do Ensino Fundamental, Ensino Médio e Ensino Superior, incluindo nossa experiência nos contextos de Educação no Campo e em Laboratório Didático de Física.

Entre os questionamentos primeiros desta reflexão que nos ajudou a definir o perfil da pesquisa, percebemos como focos de interesse situações nas quais professores e estudantes enfrentavam obstáculos na resolução de problemas matemáticos, mas encontravam soluções criativas que em certos momentos causavam encantamento ou surpresa aos sujeitos envolvidos.

Ainda nos estudos preliminares para elaboração do projeto de pesquisa, em Polya (1994), uma referência clássica do estudo da Resolução de Problema (RP), deparamo-nos com a noção de heurística, que para este autor está relacionada com o estudo dos métodos e das regras da descoberta e da invenção. Esta primeira ideia sobre a heurística nos mostrou o quanto esta noção estaria relacionada a aspectos inerentes à RP, pois, em certa medida, resolver um problema proposto, seja ele mais simples ou mais complexo, compõe um ato de descoberta, de criatividade, que desperta no indivíduo um sentimento de valorização daquilo que está se propondo a aprender.

Ainda na fase exploratória da pesquisa, deparamo-nos também com extenso número de publicações realizadas entre as décadas de 80/90 sobre RP, no Grupo de Estudos e Pesquisas em Educação Matemática (GEPEM) da Universidade Federal Rural do Rio de Janeiro (UFRRJ), grupo este que muito tematizou sobre a RP. Dentre os vários trabalhos que abordam tal tema e foram publicados no Boletim GEPEM, destaca-se o artigo de Melo Varizo (1986) no qual a autora demarca aspectos que estão diretamente relacionados às noções de heurística em Polya, como a generalização, a analogia, a decomposição e a recomposição, enfocando a necessidade de se compreender os aspectos cognitivos que estão associados a aprendizagem em matemática.

Percebemos nesta primeira revisão que havia uma lacuna, uma espécie de lapso na exploração

\footnotetext{
${ }^{1}$ Dissertação de mestrado concluída em agosto de 2014 no Programa de Pós-Graduação em Educação Matemática da Universidade Estadual de Santa Cruz (Bahia-Brasil). Agência de fomento - FAPESB.
} 
da noção de heurística, ficou adormecida, não figurando de maneira explicita em estudos posteriores.

Aprofundando um pouco mais a investigação encontramos outras definições de heurística, como a de Sagh Bazarian (1986) que afirma que a intuição heurística seria o conhecimento direto que nos faz descobrir ou criar algo novo, pressentir a verdade ou adivinhar a solução de um problema, antecipar o resultado, descobrir, criar e até adivinhar o até então desconhecido. Observamos que esta definição destaca não o método no centro, como admitiram pesquisadores filiados à ideia de Polya, mas a primazia da percepção/intuição na qual a solução de um problema prático/teórico é encontrada de modo imediato, repentino, não consciente e quase sempre sem informações suficientes.

Outra abordagem que encontramos compreende a heurística como uma atividade psíquica que, ao auxiliar sua solução (numa situação problemática), elabora uma nova estratégia que se mostra como algo inédito (NOEVICH PUCHKIN, 1969). Para este autor, uma primeira aproximação para a noção de heurística seria tomá-la como um conjunto de processos mentais mobilizados para solucionar problemas. Estes processos se vinculam às faculdades operacionais do pensamento criador científico, ou como o autor denomina de atividade heurística.

Com base nas diferentes formulações e significações acerca das noções de heurística que explicitamos, orientamos nossa investigação pelos seguintes problemas: Quais questões relacionadas à heurística nas ciências podem contribuir para reflexão sobre a abordagem de conteúdos e problemas nas aulas de Matemática? A partir destas questões, que reflexões podemos tecer sobre o ensino do conceito e das aplicações de derivada nas aulas de cálculo?

Ao definirmos estes problemas como foco de nossa pesquisa, uma etapa fundamental passou a ser a busca por compreender e discutir as visões dos autores que selecionamos a respeito da noção de heurística. Assim, o objetivo geral da nossa pesquisa foi analisar, discutir e problematizar formulações de alguns filósofos e cientistas e a respeito do conceito de heurística relacionados ao trabalho científico, com vistas a identificar e sistematizar elementos que contribuam para reflexão sobre a abordagem de problemas em sala de aula.

Parte significativa desse objetivo foi alcançada, a nosso ver, a partir da reflexão filosófica ${ }^{2}$ sobre as contribuições obtidas nas obras estudadas. Assim, um dos objetivos específicos da nossa pesquisa foi descrever e analisar as principais formulações relativas aos processos heurísticos que se evidenciaram durante a nossa investigação.

Feita a sistematização e discussão das contribuições dos autores estudados, por meio do mesmo exercício filosófico, buscamos transpor a discussão sobre os potenciais da noção de heurística para o

\footnotetext{
${ }^{2}$ Conforme aprendemos em Saviani (1994), trata-se de uma reflexão radical, rigorosa (crítica) e de conjunto sobre problemas da realidade.
} 
campo da Educação Matemática (EM). Esse foi o segundo objetivo específico de nosso estudo que pretendemos alcançar.

Para esta finalidade, lançamos mão da descrição e discussão de situações vivenciadas em nossa experiência docente, contrastando-as com as contribuições dos autores estudados. Fizemos isso não como a análise de dados empíricos coletados especificamente para uma pesquisa, mas sim como recurso de ilustração ${ }^{3}$ filosófica de ideias em um debate. Assim, nossa pesquisa continuou sendo essencialmente uma pesquisa bibliográfica, mas trouxemos para reflexão nossa experiência docente, ex post facto, revisitada, a fim de valorizá-la e facilitar ao leitor penetrar no debate conosco e refletir também sobre sua prática docente, num processo de generalização naturalística ${ }^{4}$, conforme descrito por Stake (1983).

Sob o mesmo pretexto, propomos ilustrar nossa discussão e exemplificar algumas ideias, analisando a maneira como é feita a apresentação do conceito de derivada e suas aplicações em dois livros didáticos de Cálculo que conhecemos em nossa experiência, de autoria de Richard Courant e de Louis Leithold, respectivamente. A escolha desses livros esteve relacionada à nossa percepção de diferenças na apresentação do conceito e aplicações de derivada, que nos pareceu estar relacionadas a algumas das diferentes concepções sobre heurística que estudamos.

\section{METODOLOGIA}

Visando contemplar duas formas de ver o mundo (acadêmica e docente), nossa opção metodológica foi a de realizar uma pesquisa essencialmente bibliográfica e, a partir dela, procuramos realizar uma reflexão de inspiração filosófica sobre elementos de nossa prática. Segundo Saviani (1983) o pensar filosófico é um modo de refletir sobre a realidade compatível com uma perspectiva crítica e transformadora de formação e ação docente. Isto porque o pensar filosófico é uma reflexão radical (porque busca as causas dos fenômenos, os analisa em profundidade); é rigorosa (pois considera de maneira crítica os contextos, condições de produção, a qualidade do que é pensado); é de conjunto, sistêmica (por não tentar fracionar artificialmente a realidade analisada, mas sim compreender a amplitude dos contextos e unidade de análises consideradas e realiza sempre processo de síntese articulados com as análises, de modo a recompor o todo).

Nesta perspectiva, os conhecimentos obtidos de fontes bibliográficas contribuem para análise

\footnotetext{
${ }^{3}$ Chamamos de "ilustração" porque a função das situações descritas e analisadas não é a de validar empiricamente afirmações, como acontece em algumas visões de pesquisa, mas sim a de construir um cenário que auxilie na inteligibilidade das ideias debatidas.

${ }^{4}$ Em contraposição aos processos de generalização estatísticos, muito difundidos em pesquisa sob a ótica experimentalpositivista, o autor aponta o processo de generalização naturalística como sendo um dos pilares epistemológicos das abordagens de pesquisa qualitativas.
} 
da realidade materializada a partir das visões de seus autores e em nossa reflexão nós consideramos estas realidades por eles percebidas. Contudo, é nosso objetivo refletir sobre a realidade que nos é mais próxima, aquela que vivenciamos e na qual temos expectativa de atuação transformadora. Por isso, agregamos à nossa reflexão elementos da realidade que conhecemos.

O que propomos fazer aqui é exercitar a reflexão filosófica, cientes de que trazemos para discussão experiências revistadas, ex post facto, com o recurso de ilustração, visto que a função das situações descritas e analisadas não é a de validar/provar empiricamente conjecturas e afirmações, como acontece em algumas visões de pesquisa, mas sim a de construir um cenário que auxilie na inteligibilidade das ideias debatidas. Em nossa pesquisa, a maioria dos autores traça o debate visando à compreensão sistêmica e neles nos baseamos.

Em contraposição aos processos de generalização estatísticos, muito difundidos em pesquisa sob a ótica experimental-positivista, Stake (1983) destaca que a generalização naturalística é um dos pilares epistemológicos das abordagens de pesquisas qualitativas.

Acreditamos que esta perspectiva é compatível com nossa necessidade em compreender melhor o núcleo do nosso problema de pesquisa, que é a noção de heurística e seus potenciais para reflexão e ação docentes.

\section{FUNDAMENTAÇÃO TEÓRICA}

\subsection{HEURÍSTICAS NA RESOLUÇÃO DE PROBLEMAS: CONTRIBUIÇÕES DE GEORGE POLYA E PAPPUS DE ALEXANDRIA}

Em nossa investigação, percebemos que as contribuições de George Polya nos ajudam a refletir sobre as condições de RP. Talvez Polya tenha sido o responsável pela sistematização e popularização de uma concepção de heurística que leva em consideração a análise dos processos de RP e a tomada de consciência sobre as estratégias utilizadas - concepções que durante as décadas de 80/90 ainda influenciavam grupos de estudo no país, como o GEPEM/UFRRJ, cujos alguns trabalhos já mencionamos (MELO VARIZO, 1986; SOUZA DANTAS, 1986; ALVES PEREIRA, 1987; NASSER, 1988; VIEIRA DINIZ 1988).

Segundo Polya (1994, p. 86), a "Heurística moderna procura compreender o processo solucionador de problemas, particularmente as operações mentais, típicas desse processo, que tenham utilidade POLYA (1994, p. 86)". A Matemática, na verdade, é formada por um conjunto de problemas, hipóteses e suas soluções. Estas regras e métodos são uma espécie de extensão das técnicas muito utilizadas na geometria e na álgebra, onde se supõe resolvido o problema e procura-se fazer o caminho inverso. Dessa forma, tanto no processo de reconstrução regressiva ou raciocínio regressivo, contidos no método analítico, quanto no processo de reconstrução progressiva ou raciocínio progressivo, 
contidos no método sintético, é possível perceber elementos heurísticos associados a tal tarefa, pois os mesmos realizam descobertas e comprovam certas consistências.

Para Alberto Molina (2010, p. 144), a análise grega, por si mesma, é um método de heurística matemática, no qual consiste em "buscar as possíveis hipóteses de onde uma conclusão dada é deduzida, e um método de demonstração, que consistiria em buscar conexões dedutivas entre uma proposição e um conjunto de hipóteses ALBERTO MOLINA (2010, p. 144)”.

A descrição de Pappus de Alexandria sobre a análise seria como uma espécie de movimento inverso, a fim de que o reconhecimento do fim desejado, estando sob os olhos do analista, seja realmente utilizado heuristicamente ao longo do processo analítico, sem nunca perder de vista o fato de ser, na realidade, consequente ou conclusão, cujas premissas devem ser encontradas. Para termos uma ideia mais clara do processo analítico e sintético proposto por Pappus de Alexandria, Polya (1995, p. 106) nos 'presenteia' com um exemplo não-matemático que deixa muito bem claro como se desenvolve o raciocínio a partir dos elementos de análise e síntese que compõem a resolução de um problema ou de uma demonstração formal na Matemática:

\begin{abstract}
Um homem primitivo desejava atravessar um riacho, mas não pode fazê-lo da maneira habitual porque o nível da água subiu desde a véspera. Por isso, a travessia tornou-se o objeto de um problema: "a travessia do riacho" é o $x$ deste problema primário. O homem pode lembrar-se de já ter atravessado algum outro riacho por uma árvore caída. Ele procura ao redor uma árvore caída que lhe sirva, a qual se torna a sua nova incógnita, o seu $y$. $\mathrm{O}$ homem não encontra nenhuma nessas condições, mas há muitas árvores em pé à margem do riacho; ele deseja que uma delas caísse. Ser-lhe-ia possível fazer uma árvore cair atravessada sobre o riacho? Surgem uma grande ideia e uma nova incógnita: por que meios poderia o homem derrubar a árvore por sobre o riacho?

Esta sequência de ideias deve chamar-se análise, se aceitarmos a terminologia de Pappus. Se o homem primitivo conseguir concluir a sua análise ele poderá tornar-se o inventor da ponte e do machado. Qual será a síntese? A tradução das ideias em ações. $\mathrm{O}$ ato final da síntese será a passagem do homem por sobre a árvore através do riacho (POLYA, 1995, p. 106).
\end{abstract}

O ato criativo, dessa forma, se dá na prática mesmo que esta se efetive em uma teoria, em uma obra científica. Mas, este pode se concretizar também numa tecnologia, onde poderia ser considerada como uma síntese entre a ciência e a técnica. Dessa forma, podemos conceber, com este exemplo, que a análise é tomada como a decomposição do problema em partes mais compreensíveis, e a síntese a recomposição ou a ação para se conceber a efetiva solução.

\title{
3.2 HEURÍSTICAS ASSOCIADAS ÀS ORIGENS DA CIÊNCIA MODERNA
}

O método proposto por Francis Bacon, na obra conhecida como Novum Organum, pode ser categorizado em dois blocos distintos, mas que se complementam: uma crítica destrutiva e uma construtiva. A primeira é essencial para preparar a mente humana para o processo cognitivo de construção do conhecimento, por desempenhar a função de eliminar erros, preconceitos e equívocos 
que se apropriam da inteligência humana e que, segundo Hugo Menna (2011, p. 143) é denominada de Teoria dos Ídolos; a segunda permanece organizada em duas áreas de atuação do pesquisador: uma ascendente ou indutiva e uma descendente ou dedutiva. Neste segundo bloco é que consiste a principal contribuição de natureza heurística que o método traz, esta pautando-se nos auxílios dos sentidos, d memória e d inteligência. Segundo Hugo Menna (2011, p. 377-378), este método pode ser compreendido como:

[...] dois grandes conjuntos de procedimentos - as duas vias do organum baconiano -, ambos com funções bem diferenciadas: o de ascenso cognitivo e o de descenso cognitivo. A partir desta distinção mostrei que, para Bacon, os auxílios de ascenso são heurísticas de descoberta e avaliação inicial e os de descenso são princípios avaliadores de eliminação. Em síntese, sob a distinção procedimental "invenção/juízo" - ou, em termos contemporâneos, "descoberta/justificação" - o que Bacon pretendeu com seu método foi oferecer uma nova metodologia da ciência em geral (novum organum scientiarum) isto é, uma metodologia da pesquisa que inclui etapas de geração tanto como de avaliação (HUGO MENNA, 2011, p. 377378, grifo do autor).

Dessa forma, Hugo Menna (2011, p. 382-383) considera que o método proposto por Bacon estaria estruturado na forma de máximas criativas e avaliativas, ou seja, Bacon "pretendeu fornecer heurísticas para que as pessoas, reunidas em comunidades de pesquisa, pudessem construir hipóteses científicas de qualidade HUGO MENNA (2011, p. 382-383)". As heurísticas são vistas como uma linha que conduz a razão humana à natureza e, por isso, transforma-a. Mas, em que consiste então o momento da escada ascendente? Consiste em uma sistematização substancial dos procedimentos indutivos, elevando ao status de método de inferência nas ciências naturais, ou seja, estabelece os fundamentos do método indutivo moderno.

Em René Descartes os traços de análise e síntese, preservados em Pappus de Alexandria, são retomados em sua obra intitulada 'Regras', sendo modificado e adaptado tanto à álgebra nascente como à própria geometria cartesiana, levando em consideração os novos tempos e as novas concepções científicas. Além dessa abordagem, é importante ressaltar o seu aspecto universal para o pensamento humano, pois se pretendia transcender suas aplicações na matemática.

A primeira finalidade da ciência geral para Descartes é distinguir o verdadeiro do falso e, assim, se chegar ao conhecimento de toda a verdade. Dessa forma, a análise está relacionada a aspectos $a$ priori $^{5}$ e a síntese $a$ posteriori ${ }^{6}$. $\mathrm{O}$ anterior diz respeito à disciplina da intuição e do julgamento, o posterior diz respeito a achar caminhos dedutíveis para resolver os problemas.

Segundo Loparic (2006), nos 'Elementos' de Euclides e outras obras de geometria grega

\footnotetext{
5 'A análise', diz Descartes no original latim, 'mostra a verdadeira via pela qual a coisa foi descoberta, metodicamente e como que a priori' (LOPARIC, 2006, p. 142, grifo do autor).

${ }^{6} \mathrm{Na}$ descrição da síntese, o original diz: 'A síntese', ao contrário, por um caminho oposto e como que buscado a posteriori (LOPARIC, 2006, p. 142).
} 
clássica, está presente apenas o método de síntese, ou método axiomático, diferentemente do que ficou preservado nas obras de Pappus de Alexandria. Assim, os antigos gregos não buscaram revelar e registrar o método analítico, exceto em relação ao que ficou preservado em Pappus.

Neste sentido, para Augusto Battisti (2010, p. 2), o método de análise não é de natureza puramente matemática, pois é anterior à ciência geométrica, isto é, essa seria a "razão pela qual o método poderá ser universalizado e considerado "inédito", dado que se mostrará suficientemente independente do contexto geométrico em que surgiu (AUGUSTO BATTISTI, 2010, p. 2)”.

Inferimos então que tanto as heurísticas evidenciadas por Bacon quanto por Descartes são passíveis de serem categorizados como heurísticas de segundo nível, por transcenderem a esfera de discussão em torno de problemas localizados e levantarem questões sobre o método de pensamento na matemática e nas ciências.

\subsection{HEURÍSTICAS EM CONTEXTOS MAIS ABRANGENTES DE INVESTIGAÇÃO}

Nesse terceiro nível de análise das heurísticas podemos entender que estas serviriam como uma espécie de guias que orientariam as pesquisas das teorias científicas com questões formuladas no campo da epistemologia das ciências. Segundo Lakatos $(1998$, p. 31) as realizações científicas na verdade são:

[...] programas de investigação que podem avaliar-se em termos de alterações progressivas e degenerativas de problemas; e as revoluções científicas consistem na substituição (ultrapassagem no progresso) de um programa de investigação por outro. Esta metodologia oferece uma nova reconstrução racional da ciência (LAKATOS, 1998, p. 31).

Dessa forma, as heurísticas teriam a capacidade de modificar, gerar teorias secundárias, indicar transformações que devem ser feitas no cinturão para que sejam resolvidas anomalias, como o desvio da luz em um campo gravitacional, por exemplo, indicar investigações que conduzam ao descobrimento de novos fatos e fenômenos. Enfim, a garantia de heurísticas tornaria um programa de pesquisa mais progressista em seus resultados experimentais e em suas teorias corroboradas, predizendo novos fenômenos.

Em relação à matemática, Stephen Barker (1969) nos esclarece sobre dois aspectos importantes a considerar nesse contexto. O primeiro deles é que a Matemática como projeto de ciência, valoriza conhecimentos e juízos a priori ${ }^{7}$ em detrimento dos juízos empíricos. Neste sentido, o avanço da Matemática não necessitaria ser confrontado com nenhum fenômeno das demais ciências e ela seria uma ciência pura das regularidades. Por outro lado, em domínios como os da Física as teorias

\footnotetext{
${ }^{7}$ No sentido kantiano da expressão, juízos a priori são aqueles cuja validação independe da experiência (da percepção).
} 
matemáticas cresceram em prestígio por sua aderência estrutural aos fenômenos naturais investigados - de tal forma que, mais do que simples fonte de 'ferramentas', passaram a ser consideradas modelos de raciocínio e de investigação, de modo que se tornou difícil em certos campos separar o pensamento matemático do pensamento do físico.

A questão que levantamos aqui sobre as possibilidades de interpretação de teorias matemáticas evidencia que a intuição e a experiência participaram e ainda participam do desenvolvimento da Matemática, ainda que de maneira formalizada e validada de maneira a priori, segundo Stephen Barker (1969). Não à toa as origens do Cálculo Diferencial e Integral remontam como já dissemos, a dois caminhos distintos: o de Newton (intuitivo, empírico) e o de Leibniz (formal, a priori).

Nesse sentido, a atividade científica segundo Antoine Moles (2010, p. 26) é composta por: métodos racionais - algoritmos, lógica, matemática; e técnicas de manipulação da matéria. Nela, o pesquisador mais do que descobrir a 'verdade', constrói o edifício, a representação do seu domínio próprio. A démarche intelectual do cientista se baseia na gratuidade, na filosofia do 'por que não?'. Ante a complexidade, a atitude do cientista é o da escolha.

No desenvolvimento das reflexões sobre estes contextos de investigação mais abrangentes, evidenciamos algumas abordagens que reafirmaram a heurística como uma ciência da criação e dos métodos das descobertas científicas, ampliando, assim, o quadro geral da heurística nos processos de investigação científica. Algumas destas questões nos parecem emergir ainda bem vivas em aulas de Matemática em cursos de graduação, mas as duas visões sobre a participação da experiência na produção da matemática certamente ainda influenciam divergências em aulas na Educação Básica.

\subsection{NÍVEIS DE ABRANGÊNCIA DA NOÇÃO DE HEURÍSTICA}

A partir do nosso estudo, sistematizamos uma definição geral de heurística como sendo a capacidade humana de produzir ideias na interação com outras ideias e com as condições dadas, reorganizando, recombinando ou ainda criando novas ideias - capacidade que é fomentada pela necessidade de compreender ou resolver um problema que pode se apresentar ao indivíduo desde o primeiro contato até depois de sua resolução, ainda que este não esteja bem formulado ou tenha sido bem compreendido em qualquer etapa; esteja ele completo ou não; seja de modo consciente ou não. Tal capacidade pode ser focada ou tomar como fontes de ideias tanto métodos, como conceitos ou mesmo aspectos mais incipientes do problema, como imagens e outras impressões sensoriais - estas últimas identificadas por autores como Antoine Moles (2010) e Sagh Bazarian (1986) como indicativos de que o processo racional consciente não abarca toda atividade heurística e de que processos imediatos ou que tem como base percepção abrem caminhos para atuação artística do pensamento criativo.

De modo semelhante ao que fez Antoine Moles (2010), procuramos em nossa pesquisa realizar 
o exercício intelectual de organizar as contribuições dos autores estudados a partir da amplitude/abrangência que as reflexões dos autores alcançaram, desde o nível de um problema bem situado no campo da matemática, até a discussão sobre métodos globais para fertilizar o pensamento humano com heurísticas para campos além das ciências.

Ressaltamos que esta disposição serve basicamente para fins didáticos, pois estes níveis não são como um 'muro de Berlim', eles convergem entre si, são permeáveis, articulados, não podem ser vistos, a priori, de forma isolada. Também assumimos em nosso estudo a contingência de nos limitar a um número reduzido de obras, a fim de tentar retratar o tema com maior amplitude.

Dessa forma, a nossa intenção foi organizar e sistematizar um conjunto de heurísticas que podem ser associadas à resolução criativa e inovadora de problemas e os quais podem ser agrupados, a partir da identificação e distinção durante os nossos estudos, a três dimensões básicas:

- a dimensão mais localmente relacionada a um problema que pode ser resolvido através da matemática. Sendo um problema circunscrito ao domínio matemático ou um problema em outro contexto que é solúvel por raciocínios e técnicas matemáticas, as fontes de heurística nesse nível são elementos que podem ser encontrados nas proximidades da zona de definição do problema, em seu contexto ou no exame do modelo matemático e suas propriedades;

- $\quad$ a dimensão que envolve compreensão e aplicação de métodos conhecidos, desconhecido ou inovadores das ciências. A solução do problema envolve a aplicação sobre processos e métodos mais abrangentes nas ciências. A compreensão, ainda que intuitiva, envolve reflexão sobre a adequação do método usado e suas consequências para validação do resultado;

- $\quad$ a dimensão que passa envolver métodos mais gerais do pensamento, aplicáveis não só nas ciências, mas em outros campos do pensamento humano.

Assim, para efeito didático de dar suporte a novas reflexões, inferimos que os autores estudados podem ser organizados nos seguintes níveis, a partir das noções de heurística que apresentam:

Figura 1. Níveis Epistemológicos dos Métodos Heurísticos

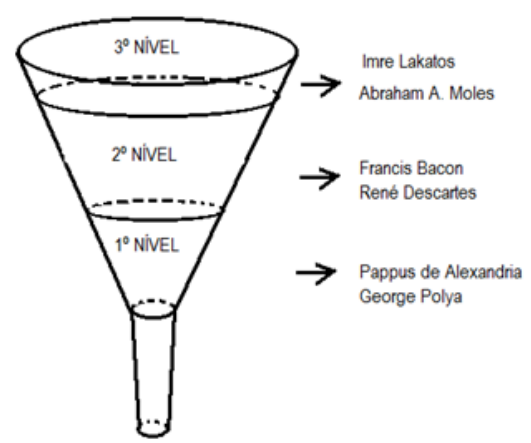

Fonte: Elaborado por Valteni Douglas Chaves. 
Nesse sentido, a heurística, este aparato ao mesmo tempo racional e perceptivo/intuitivo, ligado ao pensamento criador e inventivo humano, pode ser investigada e associada a um conjunto de questões e ideias práticas que podem ser desenvolvidas em sala de aula.

\section{CONTRIBUIÇÕES PARA A PRÁTICA DOCENTE}

A análise de livros didáticos que propusemos em nossa dissertação de mestrado é parte do exercício de transposição de nossas reflexões sobre heurística para nossa prática profissional. Neste sentido, a escolha dos livros não foi feita de forma aleatória, mas por serem conhecidos de nossa experiência como estudantes e docentes no Ensino Superior e por se revelarem dois interessantes e válidos caminhos, na medida em que enveredávamos pelos caminhos da heurística. Ambos apresentaram potencial relacionado tanto ao conceito quanto às aplicações da derivada e com as quais relacionamos com os níveis heurísticos. São eles: a) o primeiro volume do livro 'Cálculo Diferencial e Integral' de Richard Courant; b) o primeiro volume do livro 'O Cálculo com Geometria Analítica' de Louis Leithold.

Apresentamos e discutimos aqui alguns elementos da análise que fizemos, a fim de ilustrar como algumas questões levantadas em nossa pesquisa podem nos auxiliar a ver de forma diferente elementos do cotidiano profissional e, assim, a buscar novas perspectivas.

Para Courant (1963, p. 89), o conceito de derivada tem origem em duas fontes intuitivas: Fonte $\mathbf{1}$ - construção de uma reta tangente a uma curva no ponto P; Fonte $\mathbf{2}$ - pesquisa de uma definição precisa, para a velocidade, num movimento arbitrário.

A primeira delas está relacionada à tg $\alpha$, ou seja, ao ângulo de direção da curva ou inclinação gradiente - da curva. Interessante a observação que o autor faz em relação ao gradiente, pois, na Física, gradiente indica variação de intensidade de uma distribuição, estando relacionado à direção, ao movimento. Há muitos exemplos e analogias com tópicos de Física. Daí acreditar que é por esse motivo que o autor estabelece esta relação tão prematuramente no conteúdo.

Figura 2. Construção de uma reta tangente a uma curva no ponto $P$.

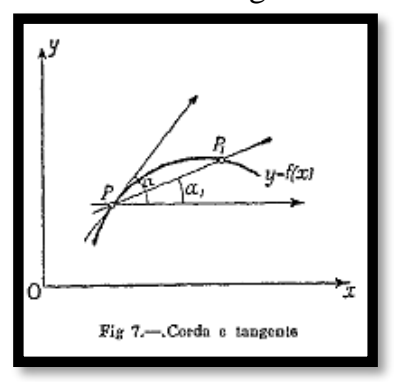

Fonte: COURANT, R. Cálculo Diferencial e Integral. 1963, p. 89. 
Na segunda fonte, Courant (1963) refere-se ao estudo da derivada como uma análise do movimento. Assim, sendo $v_{m}=\frac{f\left(t_{1}\right)-f(t)}{t_{1}-t}$ a velocidade que $t_{1}$ se aproxima cada vez mais de $t$, este limite seria a velocidade no instante $t$, isto é: $\mathrm{f}^{\prime}(\mathrm{t})=\lim _{t_{1} \rightarrow t} \frac{\mathrm{f}\left(\mathrm{t}_{1}\right)-\mathrm{f}(\mathrm{t})}{\mathrm{t}_{1}-\mathrm{t}}$. Nesse processo, o sentido analítico da derivada não possui nenhuma relação com a intuição geométrica de tangente.

Com base nessa perspectiva, em relação as aplicações de derivada, Courant (1963) aborda um aspecto geral muito relevante e que torna a relação entre a integral e a derivada mais clara. Normalmente, segundo o autor, conhecemos na natureza a Quantidade Total - $Q(t)$ e desconhecemos a densidade ou Quantidade Específica - $q(t)$. Por esse motivo, $Q(t)$ é conhecida por Primitiva e $q(t)$ é conhecida por derivada, já que deriva da primitiva.

Ao compararmos o desenvolvimento deste item entre os dois livros analisados, percebemos que a proposta inicial do Courant (1963) em realizar processos mais gerais é plenamente atingida. Quando Courant (1963) afirma que normalmente na natureza conhecemos a Quantidade Total $Q(t)$ e desconhecemos ou procuramos a Quantidade Específica $q(t)$, percebemos que os exemplos abordados por Leithold (1994) podem ser prontamente agrupados através da concepção de Courant.

Para nós, seria menos produtivo apenas observar exemplos isolados. Num exemplo típico de processo indutivo de construção de um conceito, nos sentimos capazes de fazer tal generalização de forma tão perspicaz quanto feita por Courant. Sem a percepção de tal generalização, talvez nós intuíssemos apenas exemplos isolados, sem nenhuma ou quase nenhuma correlação aparente, consistindo em apenas aplicações isoladas em áreas do conhecimento científico distintos. Esta é uma das contribuições que a nossa pesquisa deseja evidenciar, ou seja, construir princípios mais gerais de organização do conhecimento e os caminhos epistemológicos que possam conduzir a tal organização são uma boa fonte de heurística.

Associamos esta concepção aos elementos desenvolvidos aqui como heurísticas de segundo e terceiro nível porque, na abordagem do conceito matemático, a matemática é apresentada, num primeiro momento, como método de modelagem associada a um fenômeno (empírico) e sujeita a seus condicionantes indutivos; num segundo momento, a matemática é problematizada como um modo de interpretar o fenômeno e sujeita a produção de significados fora de seu campo disciplinar.

Com efeito, as abordagens analisadas se mostram mais favoráveis a estimular a emergência de heurísticas em níveis de abrangência diferentes: o livro de Leithold nos pareceu mais favorável a estimular o docente e estudante a explorar possibilidades e significados nas ideias e técnicas matemáticas em problemas gradualmente associados à estrutura, organização mais tradicional de um curso de cálculo, ainda que abordando problemas e exemplos da Física para dentro do domínio na Matemática; o livro de Courant se mostrou favorável a estimular uma reconstrução intuitiva dos 
raciocínios do Cálculo tecidos dentro dos domínios da Física - um caminho diferente do tradicional, não tão linear na apresentação dos conceitos, que subverte sua organização em prol de analisar problemas com mais dimensões desde o início, sem que se abra mão do rigor da Matemática.

Durante a análise dos livros de Cálculo Courant (1963) e de Leithold (1994), observamos que o primeiro se pautou em ideias experimentais, físicas, intuitivas, para se alcançar os processos formais do Cálculo. Não desconsideramos aqui o papel fundamental dos conhecimentos acadêmico-formais, muito pelo contrário, consideramos como algo de muita relevância e importância, especialmente pelo fato dos seus pressupostos auxiliarem tanto o campo da compreensão dos conceitos matemáticos quanto a visão sistemática do conteúdo, os quais avaliamos como essenciais no que tange à formação dos futuros educadores matemáticos.

Portanto, ao refletirmos sobre o ensino da derivada, observamos uma relação muito frutífera quando os cálculos diferencial e integral são desenvolvidos de forma concomitante, sem a primazia de um em detrimento do outro. As formulações mais amplas deste conteúdo tornam a sua compreensão mais clara e sua aplicabilidade mais significativa, pois conseguimos ter uma visão mais global dos processos.

Ainda pautados no ensino do cálculo, conjecturamos que uma prática que propõe relacionar a derivada com outros campos do conhecimento científico se revela como algo altamente fértil, especialmente quando almejamos uma visão holística deste conhecimento. Ressaltamos também, a importância do enfoque histórico acerca do conteúdo desenvolvido, buscando compreender o desenvolvimento teórico e os processos globais associados a tal desenvolvimento. Pautados nesta visão, consideramos que o livro de Courant (1963) possui um bom potencial para se desenvolver da forma mais satisfatória e ampla possível tais abordagens, pois a disposição do seu conteúdo, os problemas e exemplos propostos, bem como o contexto histórico, produzem uma melhor compreensão acerca do conceito e das aplicações da derivada, da sua relação com a integral e também com outros campos científicos.

\section{CONSIDERAÇÕES FINAIS}

De posse das questões levantadas, encontramos um vasto e fértil campo para reflexão e exploração didática da noção de heurística e a sua relação com o ensino e a aprendizagem do cálculo, para além da Matemática compreendida estritamente como técnica, na direção de incorporar dimensões de uma Matemática compreendida como arte. Esse novo olhar pode nos levar a novos caminhos e a vislumbrar novas paisagens, especialmente quando buscamos superar um embate que sempre nos pareceu mal colocado por fazer antagonizarem essas duas dimensões da Matemática que nos parecem historicamente complementares, mas que ficam polarizadas no embate dialético entre a intuição e o 
rigor - que não era tão crítico na antiguidade de nossa ciência, mas que hoje se faz sempre presente.

Dentre os futuros desdobramentos deste estudo, esperamos que sejam agregadas a ele o desenvolvimento das fontes de heurísticas que foram aqui sistematizadas e suas aplicações em estudos empíricos, buscando novas conexões, novas aplicações e, por conseguinte, novas abordagens. 


\section{REFERÊNCIAS E BIBLIOGRAFIA}

Alberto Molina, J. (2001). Lakatos como filósofo da matemática. Episteme, Porto Alegre, n. 13, p. 129153 , jul./dez.

Alves Pereira, R. (1987). Resolução de Problemas. Boletim do Grupo de Estudos e Pesquisas em Educação Matemática - GEPEM. UFRRJ: Ano XII, $2^{\circ}$ Semestre.

Antoine Moles, A. (2010). A Criação Científica. São Paulo: Perspectiva.

Augusto Battisti, C. (2010). O método de análise cartesiano e o seu fundamento. Scientiae Studia. Revista Latino-Americana de Filosofia e História da Ciência, v. 8, n. 4.

Courant, R. (1963). Cálculo Diferencial e Integral. v. 1. Rio de Janeiro: Globo.

Douglas Chaves, V. (2014). Heurística e suas possibilidades de emergência nas aulas de matemática. Dissertação (Mestrado em Educação Matemática) - Universidade Estadual de Santa Cruz - UESC. Ilhéus, Bahia, Brasil.

Hugo Menna, S. (2011). Máquinas, gênios e homens na construção do conhecimento: uma interpretação heurística do método indutivo de Francis Bacon. Tese (Doutorado) - Universidade Estadual de Campinas - UNICAMP: Instituto de Filosofia e Ciências Humanas. Campinas, SP: [s. n.].

Leithold, L. (1994). O Cálculo com Geometria Analítica. 3. ed. v. 1. São Paulo: Harbra.

Loparic, Z. (1997). Descartes Heurísticos. Coleção Trajetória - 5. Campinas: UNICAMP.

Melo Varizo, Z. da C. (1986). A Heurística e o Ensino de Resolução de Problemas. Boletim do Grupo de Estudos e Pesquisas em Educação Matemática - GEPEM. UFRRJ: Ano XI, $1^{\circ}$ Semestre.

Nasser, L. (1988). Resolução de Problemas: uma análise dos fatores envolvidos. Boletim do Grupo de Estudos e Pesquisas em Educação Matemática - GEPEM. UFRRJ: Ano XIII, $1^{\circ}$ Semestre.

Noevich Puchkin, V. (1969). Heurística: a ciência do pensamento criador. Rio de Janeiro: Zahar. Polya, G. (1994). A Arte de Resolver Problemas. Rio de Janeiro: Interciência.

- (1995). A Arte de Resolver Problemas: um novo aspecto do método matemático. Tradução e adaptação de Heitor Lisboa de Araújo - $2^{\mathrm{a}}$ reimpressão. Rio de Janeiro: Interciência.

Sagh Bazarian, J. (1986). Intuição Heurística: uma análise científica da intuição criadora. 3. ed. São Paulo: Alfa-Ômega.

Saviani, D. (1996). Educação: do senso comum à consciência filosófica. 12. ed. Campinas: Autores Associados.

Souza Dantas, M. de. (1986). Um Processo entre a Exposição e a Descoberta. Boletim do Grupo de Estudos e Pesquisas em Educação Matemática - GEPEM. UFRRJ: Ano XI, $2^{\circ}$ Semestre.

Stake, R. E. (1983). Pesquisa qualitativa/naturalista - problemas epistemológicos. Educação e Seleção, n. 7, São Paulo: Fundação Carlos Chagas, jan./jun. 
Stephen Barker, F. (1969). Filosofia da Matemática. Rio de Janeiro: Zahar.

Vieira Diniz, M. I, de S. (1988). Resolução de Problemas de Matemática Elementar. Boletim do Grupo de Estudos e Pesquisas em Educação Matemática - GEPEM. UFRRJ: Ano XIII, $1^{\circ}$ Semestre. 